\title{
Observation and Reflection on Problem-based Learning
}

\author{
Xiang Zou \\ Department of Microbiology and Immunology, Mucosal Immunobiology and Vaccine Research Center, Institute of \\ Biomedicine, University of Gothenburg, Gothenburg, Sweden \\ Email: zou.xiang@gu.se
}

\begin{abstract}
Problem-based learning (PBL) is a student-centered pedagogy in which students learn about a subject through solving purposefully designed "problem". The aim of this study was to investigate whether the PBL trains the students to develop reflective thinking and acquire the necessary skills to solve problems that were not directly related to the ones discussed in PBL. Following participation in the PBL which was incorporated in an immunology course, the students were examined on questions that can be divided into two types depending on their relatedness to the PBL questions. The result indicates that the students performed equally well on these two types of questions, confirming the build-up of general problem-solving capabilities. Strategies for further improving the PBL methodology according to various pedagogical theories and practices were also discussed.
\end{abstract}

Index Terms - problem-based learning, web-based learning, teaching method

Problem-based learning (PBL) is a student-centered pedagogical format that contrasts with the conventional teacher-centered lecture-based teaching (Wilkerson 1996). The introduction of the PBL approach has been motivated by recognition of the drawbacks of traditional instruction and the deeper understandings of how people learn (Boyer, 1998). In PBL, students are divided into working groups and are given questions that are of complex, multifaceted, and practical nature. Thus, students learn about a subject and acquire knowledge in the context of problems. Furthermore, students are oriented toward meaning-making rather than fact-collecting type of learning. They are trained to identify what they already know, what they should know, and how and where to retrieve information that may lead to the resolution of the problems. With such dynamic group work as well as both collaborative and independent investigation, the students can achieve higher levels of comprehension and develop more self-learning skills. PBL fosters the students' skills in problem solving and comprehensive thinking. In comparison to traditional instruction where knowledge is expounded by a teacher, the PBL methodology actively engages the student in constructing knowledge in their own way so as to achieve a higher quality of learning.

Although PBL was pioneered in the health sciences at McMaster University in Canada more than 40 years ago, this teaching style did not become widely accepted until recently. The first time I heard this terminology was when I participated in the teaching of the course "Basic Immunology" organized by the Department of Microbiology and Immunology in Gothenburg, 2009. I had the experience of both giving lectures in a traditional format and being a tutor in PBL group discussions. The course was composed of a total of 52 hours of lecture, 37 hours of laboratory demonstration and 18 hours of PBL tutorials. The PBL questions were carefully designed and chosen so that the students learn how to answer the questions through solving the problems. The "problems" in our PBL curricula were typically in the form of "cases", which were challenges common to the cutting edge knowledge of immunology. Students were advised to practice deductive reasoning and analyzing rather than merely memorizing.

I have participated in three rounds of teaching of the course "Basic Immunology" so far. A question that occurred to me was whether or not our PBL really trains the students to develop reflective thinking abilities. The purpose of the PBL is not simply to train the students to be able to answer the questions raised at the PBL sessions; instead, they are advised to use these questions as probes to try to understand related scientific issues in a broader sense in immunology. One way to measure if this goal has been reached is to analyze the students' examination results. We had two types of examination questions all of which were essay based. One type had a direct, more obvious relationship with the PBL questions; whereas the other type of questions was not directly related to PBL questions. In order to be able to answer them the students had to extend their scope of PBL discussions and dig deeper into the study materials.

I undertook to analyze the examination scores of the spring term of 2011. In this examination, the students were asked to answer 12 essay-based questions. Of these 12 questions, 8 were directly related to the questions in the PBL cases and 4 were not directly related to the questions in the PBL. If the PBS training could really help students develop critical thinking and draw inferences about other cases from one instance, then the students should be able to answer both types of questions equally well, irrespective of their correlation with the PBL questions. I have analyzed altogether $88 \mathrm{PBL}$ and 44 non-PBL questions answered by 11 students (Supplementary Table 1). All the raw scores were transformed into the Percentage of Total (PCT) scores. The average PCT score for PBL questions was 63.19 and the standard deviation was 30.98. The counterparts for non-PBL questions were 71.89 and 31.70, respectively (Table 1). The ANOVA analysis indicates that the PCT score is not statistically significantly different between PBL-related and 
non-related questions done by those 11 students.

Table 1. Comparison of PCT scores

\begin{tabular}{ccccc}
\hline \multirow{2}{*}{$N$} & \multirow{2}{*}{$\begin{array}{c}\text { Direct relation } \\
\text { to PBL }\end{array}$} & \multicolumn{2}{c}{ PCT score } & \multirow{2}{*}{$P$} \\
\cline { 3 - 4 } & Yes & 63.19 & Std & \\
\hline 88 & No & 71.89 & 30.98 & 0.134 \\
\hline 44 & & 31.70 & \\
\hline
\end{tabular}

Of course there are certain limitations of this study. First of all, the student number is relatively small. This might be compensated for by the question numbers. Each student answered 8 PBL-questions and 4 Non-PBL questions. Therefore, the comparisons were drawn on a total number of 88 versus 44 questions. Secondly, the relative difficultness of individual examination questions and the stringency of the marking standards for them might vary, which would form the confounding elements for the analyses. However, I do not think that these 12 questions were conceived and marked by the examiners with a strong awareness of the PBL cases. Thirdly, it can also be argued that the examination performance of the students could be solely attributed to the lectures and the laboratory demonstrations. In other words, it could be argued that the PBL had no bearing at all on the examination results. Of course this is very unlikely. Therefore, I still believe that the current observation supports my assumption that our PBL case discussions were well designed so that the training fosters learning 'transfer', that is, learning in one situation can be transferred to learning in another, through self awareness and reflective learning.

Despite the current encouraging observation, we may still try to improve the PBL methodology according to various pedagogical theories and practices.

One of the approaches is to blend PBL with the Web-based learning (WBL) (Secundo 2008; Taradi 2005). The WBL refers to communication and collaboration tools such as online forums, messaging, and e-mailing etc. WBL can be efficiently incorporated into PBL tutorials if we build a platform on the Internet which may increase the efficacy of the PBL discussions. Of course we should not forget the principle of the student centeredness (Terry Anderson, 2008). In web-based PBL, the students can interact with the tutor and other students more conveniently, which is not subject to the limitation of conventional face-to-face classroom PBL, especially time and location restrictions, for example. We do see occasions that a certain student cannot attend a particular PBL session due to course conflicts or other appointments. With the incorporation of WBL into PBL, students are allowed to learn at their own rhythm and pace. Another advantage of the web-based PBL lies in the fact that answers to the questions can bounce back and forth several times between the students and the tutor as well as among the students themselves. The students can not only find the answers in their lecture notes and textbooks, but also search the Internet conveniently for answers by making full use of the Internet resources. Thus the students may corroborate their conclusions by evidences from various sources. Students can even upload their preliminary answers on the platform for other students and the tutor to evaluate and then revise the answers with the suggestions by the tutor and their fellow students. The tutors can know what the difficult study points are with the help of the computer which may keep a record every error and revision that the students make. Therefore the tutors can revise and reformulate the study questions for the students of the next term. In addition, a combination of WBL and PBL can keep all the students involved in the learning process. We always see situations that some students are more dominant than the others in PBL discussions. Sometimes this creates problems because a few less active students are deprived of the possibility for participation. With online interactions, any student would have enough space and time to voice their opinions and thoughts which may allow the development of individual accountability. Taken altogether, online interactions brought about by WBL can make PBL a more powerful learning method.

The success of PBL-based curricula also depends on the quality of case design (Yoshioka 2003; Dolmans 1997). Immunology is a rapidly developing medical discipline and new knowledge is generated every day. The study cases should prompt the students to actively discuss the problem based on their prior knowledge. Each group or individual student then can make a hypothesis or working statement which is further revised as more information is deducted through heated debate and reasoning. Therefore, the probing questions should be designed and constructed in such a way that would stimulate the students' curiosity and inquisitiveness. The students should not just passively answer the questions at the surface. They should be encouraged to examine and try out what they already know, discover what they need to learn, and develop problem-solving skills in general. They should be prompted to investigate deeper into the cases and brain storm for every possible answer that is related to the question, including those not directly related. We also need to be aware of the fact that the students who sign up for the course Basic Immunology come from various backgrounds. Their prior knowledge in immunology-related subjects and biomedicine in general vary substantially. The PBL cases should be appropriately designed so that they are suitable for all the students.

The PBL learning methodology also requires that the tutor develop good pedagogical strategies (Chan 2008; Maudsley 1999). The role of the tutor is to provide appropriate scaffolding of the case topics, ask probing questions, excite intellectual inquisitiveness, and keep the discussions moving. The PBL tutors have to be reminded that they are 
not starring on the stage; instead, the leading roles are always played by the students. The tutors should stay attentive but refrain from too much interruption. Most importantly, tutors should not give the answers to the questions directly, instead, they should encourage and motivate the students to be active and search for needed facts and solutions themselves. One ancient Chinese philosopher once said that to teach a disciple how to fish is better than to give a fish. PBL is a good example of this pedagogical philosophy. Therefore, the role of the tutor in PBL is not "to offer fish" but rather "to teach how to catch fish". In PBL, the tutor acts as a facilitator and a mentor, but not a source of "solutions".

In conclusion, the PBL for the course "Basic Immunology" is well designed and constructed. It effectively encourages and trains the students to learn by solving problems and reflecting on their experiences. Future revision is also required to update the content so that it can maximally match the development of the field accordingly. My colleagues and I aim to build our PBL into a pedagogical entity which conforms to the pedagogical concept as conveyed by the famous quote from the poet William Butler Yeats: "Education is not the filling of a pail, but the lighting of a fire."

\section{ACKNOWLEDGEMENT}

The author would like to thank Dr Lay Hoon Seah for her constructive suggestions and professional input for the project.

\begin{tabular}{|c|c|c|c|c|c|c|}
\hline & & & PLEMENTAR & CABLE 1. & & \\
\hline Obs & $\begin{array}{c}\text { Student } \\
\text { ID }\end{array}$ & Question & Rawscore & Fullscore & PCTSCORE & PBL \\
\hline 1 & 1 & 1 & 6.0 & 8 & 75 & 1 \\
\hline 2 & 1 & 2 & 4.0 & 6 & 67 & 1 \\
\hline 3 & 1 & 3 & 6.0 & 6 & 100 & 1 \\
\hline 4 & 1 & 4 & 6.0 & 6 & 100 & 1 \\
\hline 5 & 1 & 5 & 2.5 & 6 & 42 & 2 \\
\hline 6 & 1 & 6 & 2.0 & 6 & 33 & 1 \\
\hline 7 & 1 & 7 & 7.0 & 8 & 88 & 1 \\
\hline 8 & 1 & 8 & 5.0 & 6 & 83 & 2 \\
\hline 9 & 1 & 9 & 2.0 & 6 & 33 & 1 \\
\hline 10 & 1 & 10 & 3.5 & 4 & 88 & 2 \\
\hline 11 & 1 & 11 & 7.0 & 8 & 88 & 2 \\
\hline 12 & 1 & 12 & 7.0 & 8 & 88 & 1 \\
\hline 13 & 2 & 1 & 5.5 & 8 & 69 & 1 \\
\hline 14 & 2 & 2 & 4.0 & 6 & 67 & 1 \\
\hline 15 & 2 & 3 & 2.5 & 6 & 42 & 1 \\
\hline 16 & 2 & 4 & 5.0 & 6 & 83 & 1 \\
\hline 17 & 2 & 5 & 3.5 & 6 & 58 & 2 \\
\hline 18 & 2 & 6 & 5.0 & 6 & 83 & 1 \\
\hline 19 & 2 & 7 & 7.0 & 8 & 88 & 1 \\
\hline 20 & 2 & 8 & 4.0 & 6 & 67 & 2 \\
\hline 21 & 2 & 9 & 3.0 & 6 & 50 & 1 \\
\hline 22 & 2 & 10 & 3.5 & 4 & 88 & 2 \\
\hline 23 & 2 & 11 & 4.5 & 8 & 56 & 2 \\
\hline 24 & 2 & 12 & 5.5 & 8 & 69 & 1 \\
\hline 25 & 3 & 1 & 6.0 & 8 & 75 & 1 \\
\hline 26 & 3 & 2 & 4.5 & 6 & 75 & 1 \\
\hline 27 & 3 & 3 & 4.0 & 6 & 67 & 1 \\
\hline 28 & 3 & 4 & 6.0 & 6 & 100 & 1 \\
\hline 29 & 3 & 5 & 5.0 & 6 & 83 & 2 \\
\hline 30 & 3 & 6 & 2.0 & 6 & 33 & 1 \\
\hline 31 & 3 & 7 & 8.0 & 8 & 100 & 1 \\
\hline 32 & 3 & 8 & 6.0 & 6 & 100 & 2 \\
\hline 33 & 3 & 9 & 5.5 & 6 & 92 & 1 \\
\hline 34 & 3 & 10 & 4.0 & 4 & 100 & 2 \\
\hline 35 & 3 & 11 & 7.5 & 8 & 94 & 2 \\
\hline 36 & 3 & 12 & 5.0 & 8 & 63 & 1 \\
\hline 37 & 4 & 1 & 0.0 & 8 & 0 & 1 \\
\hline 38 & 4 & 2 & 0.0 & 6 & 0 & 1 \\
\hline 39 & 4 & 3 & 0.0 & 6 & 0 & 1 \\
\hline 40 & 4 & 4 & 4.0 & 6 & 67 & 1 \\
\hline 41 & 4 & 5 & 1.0 & 6 & 17 & 2 \\
\hline 42 & 4 & 6 & 0.0 & 6 & 0 & 1 \\
\hline 43 & 4 & 7 & 0.0 & 8 & 0 & 1 \\
\hline 44 & 4 & 8 & 1.0 & 6 & 17 & 2 \\
\hline 45 & 4 & 9 & 3.0 & 6 & 50 & 1 \\
\hline 46 & 4 & 10 & 0.5 & 4 & 13 & 2 \\
\hline 47 & 4 & 11 & 4.5 & 8 & 56 & 2 \\
\hline 48 & 4 & 12 & 3.0 & 8 & 38 & 1 \\
\hline 49 & 5 & 1 & 7.5 & 8 & 94 & 1 \\
\hline 50 & 5 & 2 & 3.0 & 6 & 50 & 1 \\
\hline 51 & 5 & 3 & 6.0 & 6 & 100 & 1 \\
\hline
\end{tabular}




\begin{tabular}{|c|c|c|c|c|c|}
\hline 52 & 5 & 4 & 6.0 & 6 & 100 \\
\hline 53 & 5 & 5 & 6.0 & 6 & 100 \\
\hline 54 & 5 & 6 & 3.0 & 6 & 50 \\
\hline 55 & 5 & 7 & 8.0 & 8 & 100 \\
\hline 56 & 5 & 8 & 6.0 & 6 & 100 \\
\hline 57 & 5 & 9 & 4.5 & 6 & 75 \\
\hline 58 & 5 & 10 & 4.0 & 4 & 100 \\
\hline 59 & 5 & 11 & 6.5 & 8 & 81 \\
\hline 60 & 5 & 12 & 6.0 & 8 & 75 \\
\hline 61 & 6 & 1 & 5.5 & 8 & 69 \\
\hline 62 & 6 & 2 & 3.0 & 6 & 50 \\
\hline 63 & 6 & 3 & 6.0 & 6 & 100 \\
\hline 64 & 6 & 4 & 6.0 & 6 & 100 \\
\hline 65 & 6 & 5 & 5.0 & 6 & 83 \\
\hline 66 & 6 & 6 & 3.5 & 6 & 58 \\
\hline 67 & 6 & 7 & 6.0 & 8 & 75 \\
\hline 68 & 6 & 8 & 5.0 & 6 & 83 \\
\hline 69 & 6 & 9 & 3.5 & 6 & 58 \\
\hline 70 & 6 & 10 & 4.0 & 4 & 100 \\
\hline 71 & 6 & 11 & 8.0 & 8 & 100 \\
\hline 72 & 6 & 12 & 5.0 & 8 & 63 \\
\hline 73 & 7 & 1 & 6.0 & 8 & 75 \\
\hline 74 & 7 & 2 & 3.5 & 6 & 58 \\
\hline 75 & 7 & 3 & 6.0 & 6 & 100 \\
\hline 76 & 7 & 4 & 5.5 & 6 & 92 \\
\hline 77 & 7 & 5 & 5.0 & 6 & 83 \\
\hline 78 & 7 & 6 & 0.0 & 6 & 0 \\
\hline 79 & 7 & 7 & 7.0 & 8 & 88 \\
\hline 80 & 7 & 8 & 4.0 & 6 & 67 \\
\hline 81 & 7 & 9 & 3.5 & 6 & 58 \\
\hline 82 & 7 & 10 & 3.5 & 4 & 88 \\
\hline 83 & 7 & 11 & 8.0 & 8 & 100 \\
\hline 84 & 7 & 12 & 6.0 & 8 & 75 \\
\hline 85 & 8 & 1 & 6.5 & 8 & 81 \\
\hline 86 & 8 & 2 & 2.5 & 6 & 42 \\
\hline 87 & 8 & 3 & 3.0 & 6 & 50 \\
\hline 88 & 8 & 4 & 6.0 & 6 & 100 \\
\hline 89 & 8 & 5 & 4.0 & 6 & 67 \\
\hline 90 & 8 & 6 & 3.0 & 6 & 50 \\
\hline 91 & 8 & 7 & 8.0 & 8 & 100 \\
\hline 92 & 8 & 8 & 0.0 & 6 & 0 \\
\hline 93 & 8 & 9 & 4.5 & 6 & 75 \\
\hline 94 & 8 & 10 & 4.0 & 4 & 100 \\
\hline 95 & 8 & 11 & 0.0 & 8 & 0 \\
\hline 96 & 8 & 12 & 2.5 & 8 & 31 \\
\hline 97 & 9 & 1 & 6.5 & 8 & 81 \\
\hline 98 & 9 & 2 & 5.0 & 6 & 83 \\
\hline 99 & 9 & 3 & 3.5 & 6 & 58 \\
\hline 100 & 9 & 4 & 6.0 & 6 & 100 \\
\hline 101 & 9 & 5 & 6.0 & 6 & 100 \\
\hline 102 & 9 & 6 & 5.0 & 6 & 83 \\
\hline 103 & 9 & 7 & 7.0 & 8 & 88 \\
\hline 104 & 9 & 8 & 5.0 & 6 & 83 \\
\hline 105 & 9 & 9 & 5.0 & 6 & 83 \\
\hline 106 & 9 & 10 & 4.0 & 4 & 100 \\
\hline 107 & 9 & 11 & 7.5 & 8 & 94 \\
\hline 108 & 9 & 12 & 6.0 & 8 & 75 \\
\hline 109 & 10 & 1 & 7.0 & 8 & 88 \\
\hline 110 & 10 & 2 & 5.5 & 6 & 92 \\
\hline 111 & 10 & 3 & 5.0 & 6 & 83 \\
\hline 112 & 10 & 4 & 6.0 & 6 & 100 \\
\hline 113 & 10 & 5 & 5.5 & 6 & 92 \\
\hline 114 & 10 & 6 & 1.0 & 6 & 17 \\
\hline 115 & 10 & 7 & 5.5 & 8 & 69 \\
\hline 116 & 10 & 8 & 4.0 & 6 & 67 \\
\hline 117 & 10 & 9 & 1.5 & 6 & 25 \\
\hline 118 & 10 & 10 & 3.5 & 4 & 88 \\
\hline 119 & 10 & 11 & 7.3 & 8 & 91 \\
\hline 120 & 10 & 12 & 6.0 & 8 & 75 \\
\hline 121 & 11 & 1 & 0.0 & 8 & 0 \\
\hline 122 & 11 & 2 & 2.5 & 6 & 42 \\
\hline 123 & 11 & 3 & 0.0 & 6 & 0 \\
\hline 124 & 11 & 4 & 4.5 & 6 & 75 \\
\hline 125 & 11 & 5 & 1.5 & 6 & 25 \\
\hline 126 & 11 & 6 & 1.5 & 6 & 25 \\
\hline 127 & 11 & 7 & 1.0 & 8 & 13 \\
\hline
\end{tabular}




$\begin{array}{lllllll}128 & 11 & 8 & 2.0 & 6 & 33 & 2 \\ 129 & 11 & 9 & 0.0 & 6 & 0 & 1 \\ 130 & 11 & 10 & 3.5 & 4 & 88 & 2 \\ 131 & 11 & 11 & 0.0 & 8 & 0 & 2 \\ 132 & 11 & 12 & 1.5 & 8 & 19 & 1\end{array}$

\section{REFERENCES}

[1] Wilkerson, LuAnn and Wim H. Gijselaers, eds. (1996). "Bringing Problem-based Learning to Higher Education." New Directions for Teaching and Learning 68. Francisco: Jossey-BassSan.

[2] Boyer Commission on Educating Undergraduates in the Research University for the Carnegie Foundation for the Advancement of Teaching. (1998). Reinventing Undergraduate Education: A Blueprint for America's Research Universities. http://naples.cc.sunysb.edu/pres/boyer.nsf/ (accessed 16/6/2011).

[3] Suncana Kukolja Taradi, Milan Taradi, Kresimir Radic and Niksa Pokrajac. (2005). Blending problem-based learning with Web technology positively impacts student learning outcomes in acid-base physiology. Advan in Physiol Edu 29:35-39.

[4] Giustina Secundo, Gianluca Elia \& Cesare Taurino. (2008). Problem-Based Learning in web environments: how do students learn? Evidences from the 'Virtual eBMS' system. Int. J. Cont. Engineering Education and Lifelong Learning, Vol. 18 , No. 1.

[5] Anderson, T. (2008). Towards a Theory of Online Learning ( $\mathrm{pp}$ 44-74). In Terry Anderson (Ed.)/The Theory and Practise of Online Learning./ Athabasca University.

[6] Toshimasa Yoshioka, Yoko Uchida \& Tadahiko Kozu. (2003). Format of Cases Affects Learning Outcomes in First Year Medical Students. Education for Health, Vol. 16, No. 1, 59 - 67.

[7] Diana Dolmans, Hetty Snellen-Balendong, Ineke Wolfhagen \& Cees van der Vleuten. (1997). Seven principles of effective case design for a problem-based curriculum. Medical Teacher, Vol. 19, No. 3.

[8] Gillian Maudsley. (1999). Roles and responsibilities of the problem based learning tutor in the undergraduate medical curriculum. BMJ VOLUME $3186 \mathrm{MARCH}$.

[9] Li Chong Chan. (2008). The role of a PBL tutor: A personal perspective. Kaohsiung J Med Sci 2008; 24 (3 Suppl): S34-8.

Xiang Zou was born in Nanjing, China. He received his bachelor's degree from Nankai University, Tianjin, China and Ph. D. from Uppsala University, Uppsala, Sweden. He is currently a docent in the University of Gothenburg, Sweden. His research interests include immunology and pedagogy. 